\section{Bile intraductal aspiration (BIDA): a fast method for bile collection}

Microbiological analysis of bile can be a valuable diagnostic tool, which may lead to better therapy and help in the establishment of local antibiotic guidelines for the management of cholangitis. However, it is not generally recommended and is rarely performed because it appears to be technically demanding, time consuming, or unnecessary in the presence of blood cultures [1]. In this report, we describe a new endoscopic technique for bile aspiration that has been devised at our institute, which we have named BIDA (Bile IntraDuctal Aspiration).

Cholangiography is performed with endoscopic and radiologic control using var- ious types of catheter, such as a papillotome, a balloon-catheter, or biliary cannula, depending on the individual case. The site of aspiration is first identified, and then a sterile, 40 -mL specimen trap (Kendall Argyle; Tyco Healthcare Group, Mansfield, Massachusetts, USA) is connected to both the catheter that has been placed in the bile duct and the central suction line, which has a pressure of 0.6 bar. The catheter is moved back and forth slowly during aspiration to avoid mucosal injury related to the suction. To prevent contamination of the bile, the catheter is kept within the bile duct during BIDA. Suction is discontinued when at least $2 \mathrm{~mL}$ of bile has been obtained ( $\bullet$ Fig. 1 ). The specimen trap is then disconnected from the catheter and sent directly to the laboratory for antibiotic susceptibility testing and bacterial resistance profiling.

The development of a rapid and widely applicable bile aspiration technique that can be performed during endoscopic cholangiography could help avoid delays in diagnosis and the need for additional procedures, as well as reducing healthcare costs. The technique has now been used routinely and successfully for 1 year, during which time we have found BIDA to be simple, rapid, economical, and safe. It is also versatile because it can be performed with any type of biliary catheter. In conclusion, BIDA could prove to be a useful and potentially widely applicable new technique for bile aspiration, which could allow microbiological evaluation of bile whenever needed.
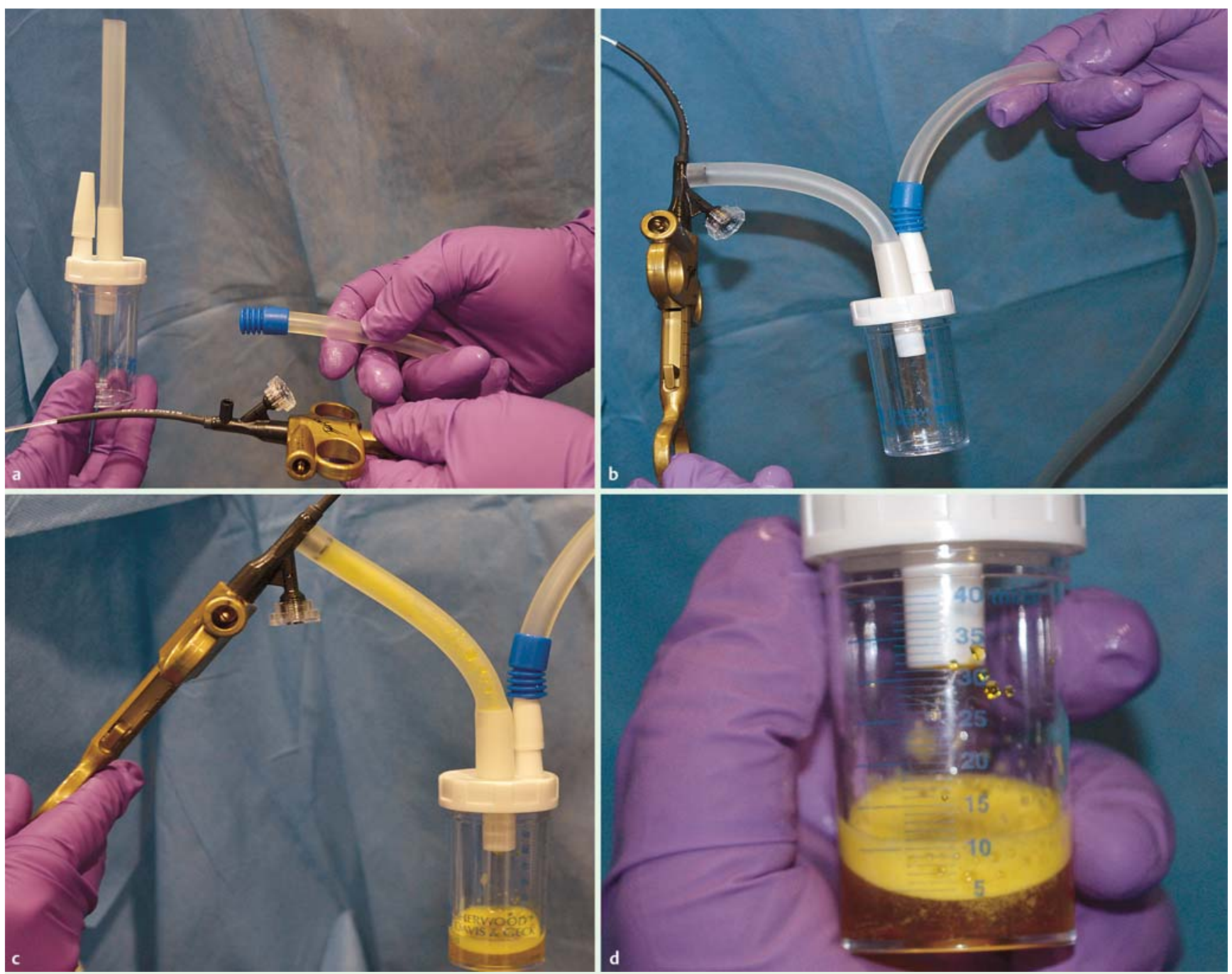

Fig. 1 Images taken during the bile intraductal aspiration (BIDA) procedure showing: a the specimen trap, catheter, and suction line that are used before connection; $\mathbf{b}$ the three components connected together; $\mathbf{c}$ the flow of bile through the suction line; $\mathbf{d}$ the bile collecting within the specimen trap. 
Endoscopy_UCTN_Code_TTT_1AR_2AD

Competing interests: None

G. Curcio, A. Granata, L. Barresi, I. Tarantino, F. Mocciaro, M. Traina

Gastroenterology and Endoscopy Unit, Mediterranean Institute for Transplantation and Advanced Specialized Therapies (IsMeTT), Palermo, Italy

\section{References}

1 Negm AA, Schott A, Vonberg RP et al. Routine bile collection for microbiological analysis during cholangiography and its impact on the management of cholangitis. Gastrointest Endosc 2010; 72: 284-291

\section{Bibliography}

DOI http://dx.doi.org/

$10.1055 / \mathrm{s}-0031-1291644$

Endoscopy 2012; 44: E230-E231

(c) Georg Thieme Verlag KG

Stuttgart · New York

ISSN 0013-726X
Corresponding author

\section{G. Curcio, MD}

Gastroenterology and Endoscopy Unit IsMeTT, UPMC

Via Tricomi 1

Palermo 90127

Italy

Fax: +39-091-2192400

gcurcio@ismett.edu 